\title{
Implementation of FC-TCR for Reactive Power Control
}

\author{
Ms.K.Sree Latha ${ }^{1}$, Dr.M.Vijayakumar ${ }^{2}$ \\ ${ }^{I}$ Assoc.Prof(Eee), Gnitc, Hyderabad \\ ${ }^{2}$ Professor, Jntu, Anantapur
}

\begin{abstract}
This paper deals with the simulation and implementation of fixed capacitor thyristor controlled reactor system(SVC). The TCR system is simulated using MATLAB and the simulation results are presented. SVC is basically a shunt connected static var generator whose output is adjusted to exchange capacitive or inductive current so as to maintain or control specific power variable. In this paper, simple circuit model of Thyristor Controlled Reactor is modeled and simulated using MATLAB. The simulation results are presented. The current drawn by the TCR varies with the variation in the firing angle. The simulation results are compared with the theoretical results.
\end{abstract}

Key Words: Static VAR Compensators, FC-TCR, MATLAB, Simulink, Reactive Power

\section{Introduction}

Modern power system is complex and it is essential to fulfill the demand with better power quality. Advanced technologies are nowadays being used for improving power system reliability, security and profitability and due to this power quality is improved. Voltage stability, voltage security and power profile improvement are essential for power quality improvement. To achieve optimum performance of power system it is required to control reactive power flow in the network. Construction of new transmission lines and power stations increase the problem of system operation as well as the overall cost. Regulatory limitation on the expansion of system network has resulted in reduction in stability margin thereby increasing the risk of voltage collapse [3]. Voltage collapse occurs in power system when system is faulted, heavily loaded and there is a sudden increase in the demand of reactive power. Voltage instability in power system occurs when the system is unable to meet the reactive power demand.

Reactive power imbalance occur when system is faulted, heavily loaded and voltage fluctuation is there. Reactive power balance can be regained by connecting a device with the transmission line which can inject or absorb reactive power based on system requirement [4].One of the most important reactive power sources is FACTS (Flexible A.C transmission system) device. FACTS may be defined as a power electronic based semiconductor device which can inject or absorb reactive power in a system as per requirement. This device allows "Flexible" operation of an AC system without stressing the system.

FACTS are a family of devices which can be inserted into power grids in series, in shunt, and in some cases, both in shunt and series. FACTS mainly find applications in the following areas:

- Power transmission

- Power quality

- Railway grid connection

- Wind power grid connection

- Cable systems

With FACTS, the following benefits can be attained in AC systems:

- Improved power transmission capability

- Improved system stability and availability

- Improved power quality

- Minimized environmental impact

- Minimized transmission losses

FACTS are a family of devices which can be inserted into power grids in series, in shunt, and in some cases, both in shunt and series.

\section{A. Shunt Device}

(1) Static Var Compensator:

(2) Static Synchronous Compensator

(STATCOM)

B. Series Device

(1) Thyristor Controlled Series Compensator (TCSC)

(2) Static Synchronous Series Compensator (SSSC) 
Important applications in power transmission and distribution involve devices such as SVC (Static Var Compensators), Fixed Series Capacitors (SC) as well as Thyristor-Controlled Series Capacitors (TCSC) and STATCOM.

\section{Static Var Compensator}

Static VAR systems are applied by utilities in transmission applications for several purposes. The primary purpose is usually for rapid control of voltage at weak points in a network. Installations may be at the midpoint of transmission interconnections or at the line ends [3]. Static Var Compensators are shunt connected static generators / absorbers whose outputs are varied so as to control voltage of the electric power systems.

An SVC can improve power system transmission and distribution performance in a number of ways. Installing an SVC at one or more suitable points in the network can increase transfer capability and reduce losses while maintaining a smooth voltage profile under different network conditions. The dynamic stability of the grid can also be improved, and active power oscillations mitigated.

An SVC fig. 1 typically comprises a transformer, reactors, capacitors and bi-directional thyristor valves. There is a variety of main circuit arrangements.

- FC/TCR - Fixed Capacitor (filter) / Thyristor-Controlled Reactor.

-TSC/TCR-Thyristor-Switched Capacitors/Thyristor-

Controlled Reactor.

In its simple form, SVC is connected as Fixed Capacitor-Thyristor Controlled Reactor (FC-TCR) configuration as shown in Fig. 1

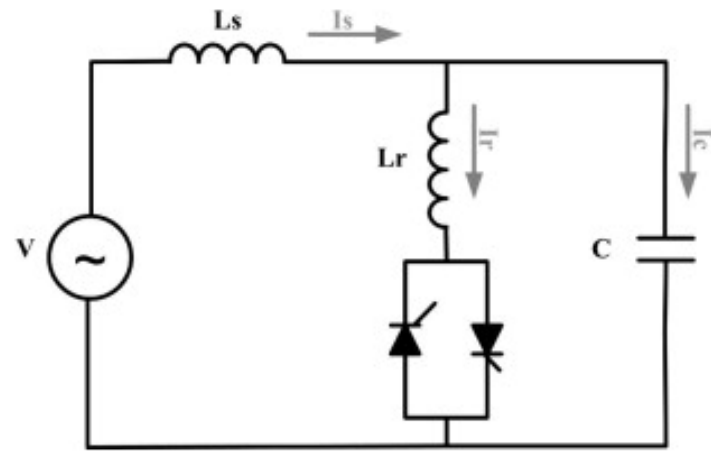

Fig.1 Fixed capacitor thyristor controlled reactor

A TCR is one of the most important building blocks of thyristor-based SVCs. although it can be used alone, it is more often employed in conjunction with fixed or thyristor-switched capacitors to provide rapid, continuous control of reactive power over the entire selected lagging to leading range.

In FC-TCR, a capacitor is placed in parallel with a thyristor controlled reactor. Is, Ir and Ic are system current, reactor current and capacitor current respectively which flows through the FC-TCR circuit. Fixed capacitor- Thyristor controlled reactor (FC-TCR) can provide continuous lagging and leading VARS to the system [5]. Circulating current through the reactor (Ir) is controlled by controlling the firing angle of back-back thyristor valves connected in series with the reactor. Leading var to the system is supplied by the capacitor. For supplying lagging vars to the system, TCR is generally rated larger than the capacitor.

\section{Operating Principle And Modelling Of Svc}

An elementary single phase thyristor controlled reactor [1] (TCR) shown in Fig.1 consists of a fixed (usually air core) reactor of inductance L and a two anti parallel SCRs. The device brought into conduction by simultaneous application of gate pulses to SCRs of the same polarity. In addition, it will automatically block immediately after the ac current crosses zero, unless the gate signal is reapplied. The current in the reactor can be controlled from maximum (SCR closed) to zero (SCR open) by the method of firing delay angle control. That is, the SCR conduction delayed with respect to the peak of the applied voltage in each half-cycle, and thus the duration of the current conduction interval is controlled. This method of current control is illustrated separately for the positive and negative current cycles in Fig. 2 where the applied voltage $\mathrm{V}$ and the reactor current $\operatorname{iL}(\alpha)$ at zero delay angle (switch fully closed) and at an arbitrary $\alpha$ delay angle are shown. When $\alpha=0$, the SCR closes at the crest of the applied voltage and evidently the resulting current in the reactor will be the same as that obtained in steady state with a permanently closed switch. When the gating of the SCR is delayed by an angle $\alpha(0 \leq \alpha \leq$ $\pi / 2$ ) with respect to the crest of the voltage, the current in the reactor can be expressed [1] as follows

$$
\mathrm{V}(\mathrm{t})=\mathrm{V} \cos \omega \mathrm{t}
$$




$$
\mathrm{i}_{\mathrm{L}}=(1 / \mathrm{L}) \int_{\alpha}{ }_{\alpha}^{\mathrm{wt}} \mathrm{V}(\mathrm{t}) \mathrm{dt}=(\mathrm{V} / \omega \mathrm{L})(\sin \omega \mathrm{t}-\sin \alpha)----(2)
$$

Since the SCR, by definition, opens as the current reaches zero, is valid for the interval $\alpha \leq \omega \mathrm{t} \leq \pi-\alpha$. For subsequent negative half-cycle intervals, the sign of the terms in equation (1) becomes opposite. In the above equation (1) the term $(\mathrm{V} / \omega \mathrm{L}) \sin \alpha=0$ is offset which is shifted down for positive and up for negative current half-cycles obtained at $\alpha=0$, as illustrated in Fig.2. Since the SCRs automatically turns off at the instant of current zero crossing of SCR this process actually controls the conduction intervals (or angle) of the SCR. That is, the delay angle $\alpha$ defines the prevailing conduction angle $\sigma(\sigma=\pi-2 \alpha)$. Thus, as the delay angle $\alpha$ increases, the corresponding increasing offset results in the reduction of the conduction angle $\sigma$ of the SCR, and the consequent reduction of the reactor current. At the maximum delay of $\alpha=\pi / 2$, the offset also reaches its maximum of $\mathrm{V} / \omega \mathrm{L}$, at which both the conduction angle and the reactor current becomes zero. The two parameters, delay angle $\alpha$ and conduction angle $\sigma$ are equivalent and therefore TCR can be characterized by either of them; their use is simply a matter of preference. For this reason, expression related to the TCR can be found in the literature both in terms of $\alpha$ and $\sigma$ [1].
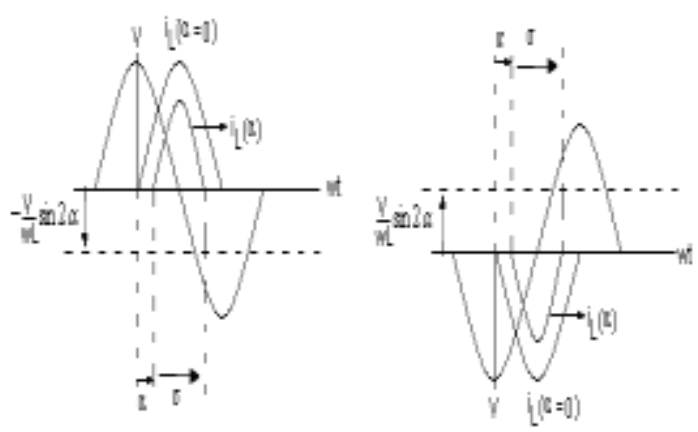

Fig.2. FIRING DELAY ANGLE

\section{Modelling Of FC-TCR}

The control objective of SVC is to maintain the desired voltage at a high voltage bus [6, 7]. In steadystate, the SVC will provide some steady- state control of the voltage to maintain it the highest voltage bus at the pre-defined level.

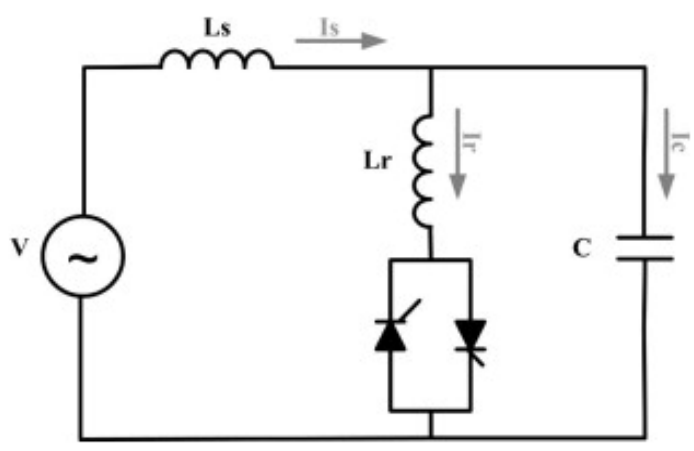

Fig.3 Basic FC-TCR type static var compensator

If the voltage bus begins fall below its set point range, the SVC will inject reactive power (Q net) into the system (within its control limits), thereby increasing the bus voltage back to its desired voltage level. If bus voltage increases, the SVC will inject less (or TCR will absorb more) reactive power (within its control limits), and the result will be to achieve the desired bus voltage. The Fixed Capacitor Thyristor-Controlled Reactor (FCTCR)[8] is a var generator arrangement using a fixed (permanently connected) capacitance with a thyristor controlled reactor as shown in Fig.3

\section{Simulation Results And Discussions}

For the AC voltage source is of $11 \mathrm{KV}, 60 \mathrm{~Hz}$, line $\mathrm{R}=5 \Omega$ \& $\mathrm{L}=60 \mathrm{mH}$, Load $\mathrm{R}=1 \Omega$ \& $\mathrm{L}=50 \mathrm{mH}$.Current measurement block is used to measure the instantaneous current flowing in the transmission line. The voltage measurement block is used to measure the source voltage. Scope displays the signals generated during a simulation. In Fig.6, scope is used to view the line current and in Fig.5 line voltage. The real power and reactive power in the load is measured using the Active \& Reactive Power measurement block.ac source voltage. 


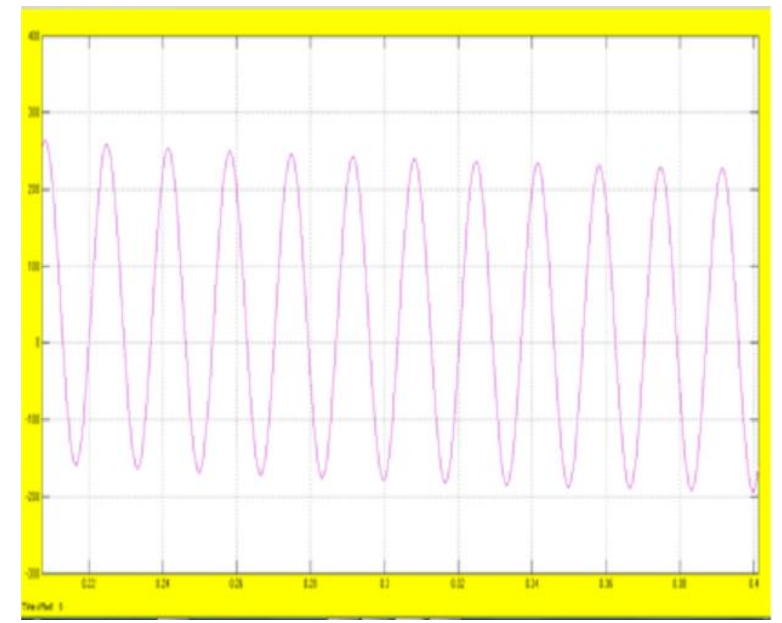

Fig.5 Line voltage

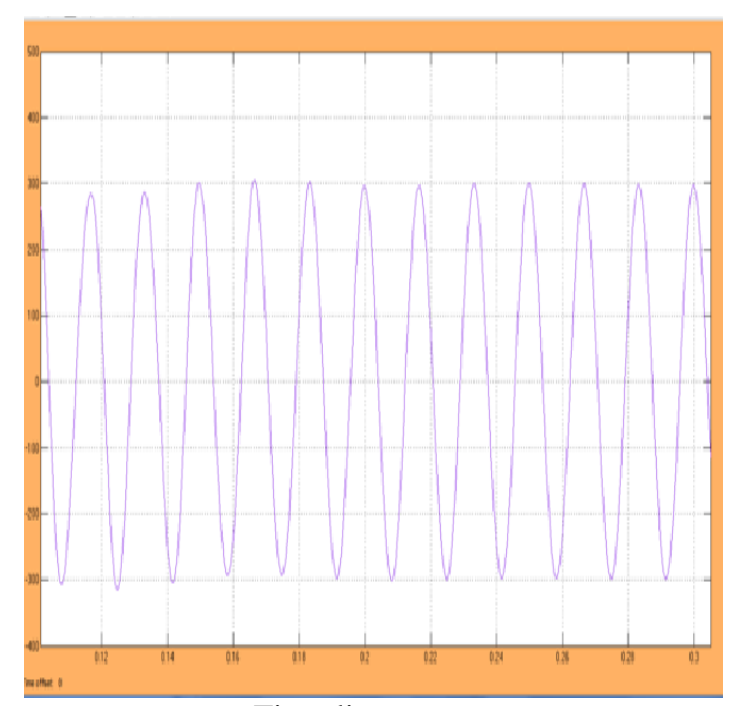

Fig.6 line current

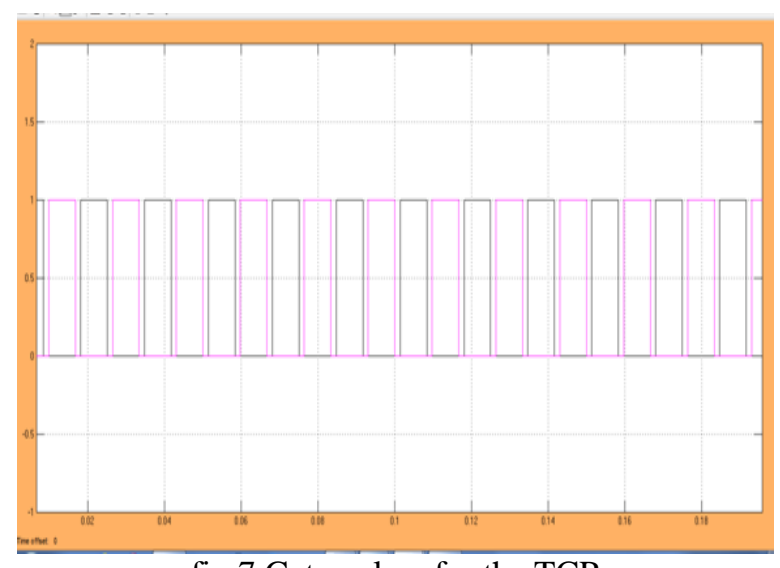

fig.7 Gate pulses for the TCR 


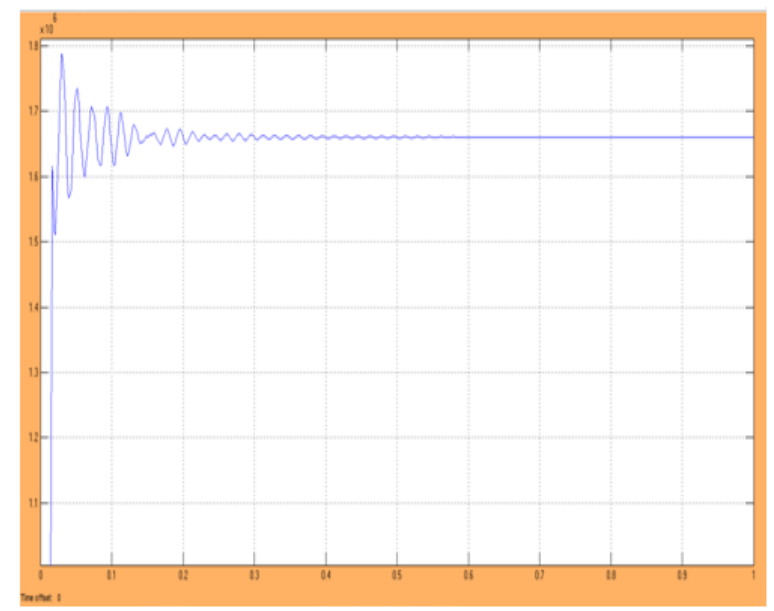

Fig.8 Reactive power waveform

Table. 1 capacitor constant and inductor varying

\begin{tabular}{|l|l|l|}
\hline Capacitor $(\mu \mathrm{F})$ & Inductor $(\mathrm{mH})$ & $\mathrm{Q}($ Vars $)$ \\
\hline 100 & 100 & 1.66 \\
\hline 100 & 150 & 2.064 \\
\hline 100 & 200 & 2.323 \\
\hline 100 & 250 & 2.502 \\
\hline 100 & 300 & 2.633 \\
\hline 100 & 350 & 2.733 \\
\hline
\end{tabular}

From the above table it is observed that by keeping capacitor constant and by varying inductor the reactive power is increasing. this shows that the reactive power can be controlled and hence the stability of the system can be increased by using FC-TCR.

\section{Conclusion}

Thus from the above result it is conclude that the Static var compensator(SVC) will control the voltage stability of the system and also maintains the dynamic performance of the system. the range of the reactive power control can be decided based on the thyristor controlled reactor and fixed capacitor. From the simulation results it is observed that reactive power variation is smoother by usig FC-TCR.

\section{References}

[1] Nang Sabai, and Thida Win "Voltage control and dynamic performance of power transmission system using SVC" World Academy of Science, Engineering and Technology Pp. 425-429 2008.

[2] Gomez A., F.Gonzalez, C.Lzquierdo C, T.Gonzalez and F.Pozo,1992. Microprocessor based control of and SVC for optimal load Compensation. IEEE Trans. Power Deliv., 7(2):706-712

[3] Narain. G. Hingorani, "Understanding FACTS, Concepts and Technology Of flexible AC Transmission Systems", by IEEE Press USA

[4] R.M. Mathur and R.K. Varma, Thyristor-Based FACTS Controllers for Electrical Transmission Systems, IEEE Press and Wiley Interscience, New York, USA, Feb. 2002.

[5] IEEE Power Engg. Society/CIGRE, "FACTS Overview", Publication 95 TP 108, IEEE Press, New York, 1995. 